\title{
"QUANDO MATO VIRA BOSQUE É PORQUE MELHOROU, NÃO É?” MOBILIDADES E PERMANÊNCIAS CONSTITUINDO TERRITÓRIOS URBANOS
}

\author{
FERNANDA CRISTINA DE PAULA ${ }^{1}$ \\ EDUARDO MARANDOLA JR. ${ }^{2}$ \\ DANIEL JOSEPH HOGAN ${ }^{3}$ \\ Universidade Estadual de Campinas
}

As cidades brasileiras cresceram nos últimos 40 anos seguindo um padrão de periferização, ou seja, a formação de periferias afastadas do centro e dos bairros consolidados, com carências de infraestrutura e de todo o tipo de equipamentos urbanos (MARICATO, 2001). Essas periferias se sucedem à medida que a expansão das cidades continuou ao longo dos anos, formando um extenso conjunto de periferias que, na maioria dos casos, vai perdendo sua condição de precariedade à medida que consolida sua urbanização e que a primeira geração (formada por jovens e crianças) amadurece e consegue acumular condições (materiais, sociais e simbólicas) para a melhoria de suas próprias condições de vida. Observa-se, então, um processo de diferenciação interna.

Esses bairros e pessoas, afastados de serviços e do próprio mercado de trabalho, vivem, no momento de sua instalação, um conjunto de riscos provenientes da própria estrutura urbana (ou da falta dela) e de sua própria condição demográfica e familiar. Esses indivíduos podem ser vistos como aqueles que vivem em uma condição de vulnerabilidade generalizada (KOWARICK, 2002; BILAC, 2006). Essa vulnerabilidade envolve riscos e

Geógrafa, mestranda em Geografia, Instituto de Geociências, Universidade Estadual de Campinas. fernanda.paula@ige.unicamp.br

${ }^{2}$ Geógrafo, pesquisador colaborador do Núcleo de Estudos de População, Universidade Estadual de Campinas. eduardom@nepo.unicamp.br

${ }^{3}$ Demógrafo, Pesquisador do Núcleo de Estudos da População, Universidade Estadual de Campinas. hogan@ nepo.unicamp.br 
perigos ambientais, sociais e sociodemográficos de diferentes ordens, envolvendo a própria condição dos domicúlios, do estágio no ciclo vital, das condições ambientais e do conhecimento que as pessoas têm do novo lugar onde estão morando (não raro, bairros com muitos migrantes) (HOGAN e MARANDOLA JR., 2006).

O processo de consolidação urbana, no entanto, estabelece melhorias sucessivas, que fornecem às pessoas a possibilidade de responder aos riscos e perigos de forma cada vez mais eficiente, tornando a condição de vulnerabilidade do princípio gradativamente menos significativa. Salvo as melhorias estruturais que evidentemente estão na base desta melhora das condições de vida, procuramos refletir neste texto acerca do papel desempenhado pelo desenvolvimento de uma identidade territorial vinculada ao bairro, o que estabelece a condição primeira para que esta capacidade de resposta aos riscos e perigos se torne cada vez mais efetiva. $\mathrm{O}$ argumento passa pelo entendimento de que a primeira condição para que as pessoas desses bairros possam lidar simbolicamente com os perigos é o estabelecimento de rotinas espaço-temporais coletivamente compartilhadas, que esteiam uma história e uma identidade territorial do bairro. Isso só se torna possível quando se estabelecem as condições de mobilidade (acessibilidade às outras partes da cidade) e de permanência no bairro (satisfação das necessidades básicas).

Essas questões foram investigadas no bairro DICs (Distritos Industriais de Campinas), na cidade de Campinas, no Estado de São Paulo. Embora tenha o nome no plural, os DICs são entendidos como um único bairro na cidade. Esta pesquisa faz parte de um esforço de estudo do bairro enquanto unidade geográfica que permite pensar as questões urbanas no âmbito da experiência. Seguindo uma tradição de estudos humanistas, de orientação fenomenológica, a pesquisa visa pensar e compreender os fenômenos em tela na forma como aparecem na experiência, revelados pelas narrativas e história de vida das pessoas (PICKLES, 1988; HOLZER, 1998; MARANDOLA JR., 2005). Envolve, portanto, práticas de metodologias qualitativas no que tange ao envolvimento do pesquisador com o lugar e as pessoas, entendendo-o como sujeito do processo de conhecimento (HAY, 2005).

$\mathrm{O}$ trabalho de campo intensivo, visando o envolvimento e a passagem de "de fora" (outsider) para "de dentro" (insider) (BECKER, 1997), é a estratégia metodológica privilegiada, envolvendo conversas biográficas semi ou não estruturadas (MARANDOLA JR., 2008a). A pesquisa foi realizada no período de junho de 2006 a junho de 2007, com retornos pontuais para fotos e adequação do mapeamento em 2008 e em 
2009, permitindo-nos, a partir da memória revelada pelos moradores em suas narrativas, pensar a formação da identidade territorial vinculada à consolidação da condição urbana desse espaço e da própria forma como os moradores aprenderam a resolver e lidar com os problemas do bairro.

\section{O início dos DICs: mobilidades e permanências}

Os DICs são um bairro residencial construído na fronteira urbanorural (da época) para atender a uma classe econômica específica (classes baixa e médio-baixa). Inserido em um projeto de habitação popular realizado pela COHAB/Campinas (Companhia de Habitação Popular de Campinas) em acordo com a Prefeitura Municipal, já surgiu com a insígnia de bairro popular (Figura 01).

Os conjuntos habitacionais são divididos como DIC I, II, III, IV, V, VI e DIC 5 de Março (Figura 2). As habitações, entregues entre final da década de 1970 e meados da década de 1990, se dividem em dois tipos: as mononucleares e os condomínios de edifícios (com espaço interno para pátios e garagens). Cada edifício tem quatro andares, com dois apartamentos em cada um. As habitações, inicialmente padronizadas, são traço forte da paisagem dos DICs, testemunhando a extensão deste conjunto habitacional e seus limites. 


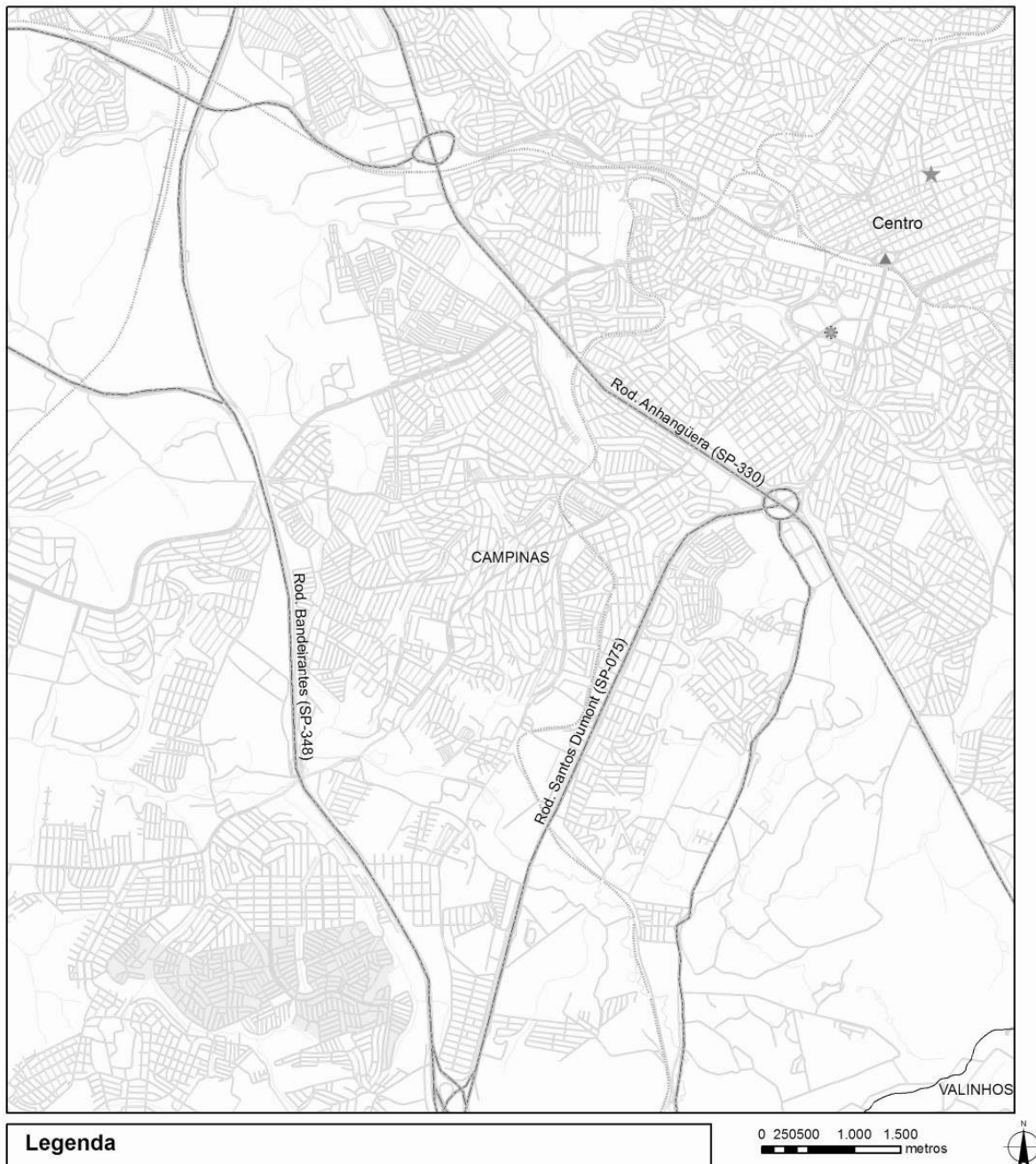

Convenções cartográficas Locais de Campinas

$\begin{array}{lll}\text { arruamento } & \text { Hospital Municipal Mário Gatti } \\ \text { rodovias } & \star \quad \text { Prefeitura Municipal de Campinas } \\ \text { rios } & 4 \quad \text { Terminal Central } \\ \text { ferrovias } & \text { DICs }\end{array}$

Base cartográfica: Empresa Paulista de Planejamento Metropolitano S.A. (EMPLASA), 2003.

South American Datum 1969, UTM 23S Projeção Transversal de Mercartor

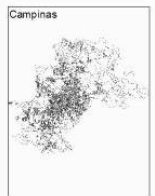

Elaboração: DE PAULA, Fernanda C.

Figura 01: Localização dos DICs na cidade de Campinas 


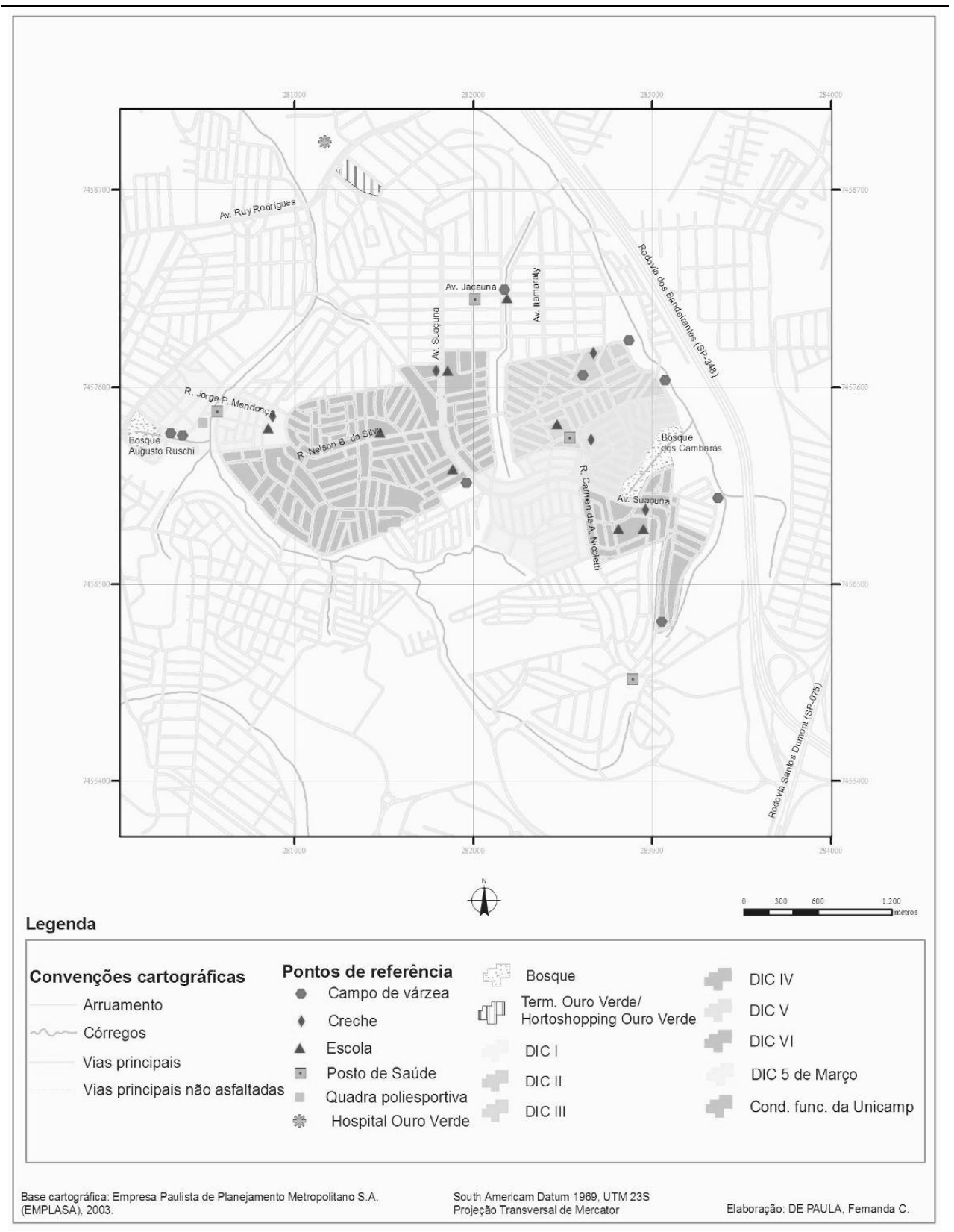

Figura 02: Os DICs seus territórios 
Construído para ser bairro popular e radicado onde a infraestrutura urbana era ainda deficitária, os DICs surgem no imaginário de Campinas como a segunda periferia da cidade. Essa afirmação faz alusão à considerável distância entre esse conjunto habitacional e o centro da cidade, denotada pela proximidade dos DICs com a Rodovia Bandeirantes (SP-348) - que servia como referência de limite (longínquo) da expansão da cidade.

Um antigo morador do DIC I atenta que, ao redor dos primeiros condomínios e das primeiras casas, havia somente mato e sítios. Assim, o início dos DICs foi caracterizado por moradias inseridas em uma paisagem urbana marcada pela condição de fronteira, faixa transacional onde urbano e rural se misturam (MARANDOLA JR., 2008b). Uma vez que a configuração da paisagem da cidade tem importância na realização das atividades mais características da vida na urbe (LEMENHE, 1997), esta condição de fronteira dos DICs é fundamental para compreendê-lo em seu momento de constituição e no processo de consolidação de sua condição urbana.

Para tanto, cabe perguntar: quais elementos são característicos da condição urbana, de um espaço citadino? Qual a diferença, em termos da organização da vida diária, de habitar uma cidade? Embora não haja uma definição universal da cidade ou do urbano (especialmente na contemporaneidade, com a diversificação dos espaços e sua crescente integração em redes cada vez mais abrangentes), podemos pensar em alguns elementos que compõem traços essenciais da cidade. Entre estes, o mais antigo talvez seja sedentarismo, que estabeleceu a fixidez dos grupos humanos, possibilitando a sua aglomeração independente da realização de atividades primárias para a subsistência. Esta independência está, por sua vez, ligada - como propulsora ou como consequência - ao crescimento e complexificação de atividades ou papéis sociais e culturais. É nesta característica que a própria paisagem urbana está fundamentada, expressa pela densidade e intensidade das atividades e do espaço construído (MUMFORD, 1982; CASTELLS, 1983; GEORGE, 1983; SERRA, 1987).

Enquanto espaço de fixidez, o urbano também é o espaço do movimento, conforme reflete Raymond Ledrut:

[...] fixação e movimento, instalação e circulação são duas categorias essenciais à vida dos aglomerados importantes. $\mathrm{O}$ drama da organização e do funcionamento das coletividades urbanas se desenvolve em torno destes dois protagonistas. Os homens ocupam uma casa sobre uma parcela de certo 
território para aí morar ou, algumas vezes, para produzir; porém se deslocam para encontrar confrades e amigos, para comprar e vender, etc. (LEDRUT, 1971, p. 101 - grifos nossos).

A cidade, além de se caracterizar pela fixidez (característica compartilhada pelo rural), potencializa o movimento por aglomerar serviços, pessoas, atividades, lugares. $\mathrm{Na}$ cidade, cada atividade implica um deslocamento, fazendo da vida cotidiana urbana um ir e vir da permanência (fundada na casa) por lugares e atividades diferentes. Tanto quanto a fixidez, a mobilidade é um traço essencial da cidade.

No processo de expansão da cidade, esses elementos são pensados em termos de bairro. Permanecer no bairro depende de condições de fixidez, ao mesmo tempo que envolve condições de mobilidade (poder ir e vir). Nos DICs, essas questões se revelam de forma especialmente significativa, ajudando-nos a compreender a mudança no sentido da vulnerabilidade e a constituição da identidade territorial do bairro.

Se o urbano é tributário da mobilidade, como afirmou Ledrut (1971), a acessibilidade está na base de uma boa condição urbana. $\mathrm{O}$ início dos DICs era marcado, no entanto, pela desconexão, pela grande distância e pelo barro nas ruas. Na década de 1980, quando em dias de chuvas muito forte, as ruas de terra se tornavam intransitáveis, e as pessoas eram obrigadas a desembarcar dos ônibus nas imediações do que é hoje o Terminal Ouro Verde e seguir até o DIC I a pé.

Não é sem fundamento a pilhéria, entre os campineiros, com a sigla dos DICs ("Distância Incalculável de Campinas"), o que aparece nas narrativas e nos relatos de seus moradores. A pouca acessibilidade diz respeito tanto à infraestrutura urbanística quanto ao sistema de transporte coletivo (itinerários e frequência). A distância em relação ao centro da cidade não se limitava, portanto, à distância física, mas era decorrente sobretudo da acessibilidade. As narrativas revelam um sentimento de isolamento do bairro em relação ao restante da cidade, além de uma insatisfação com a necessidade de ter de se deslocar para satisfazer necessidades básicas, pois tanto comércio quanto serviços públicos ou privados não existiam no bairro.

O bairro encontrava-se, portanto, descoberto de sistemas locais de proteção. Riscos e perigos eram contornados sempre com o auxílio imediato dos vizinhos, destacando o papel das redes sociais na capacidade de resposta das pessoas, especialmente em uma época em que veículos próprios ou telefones particulares eram raridade. Até o final da década de 
1990, o Pronto Socorro mais próximo era o Hospital Municipal Dr. Mário Gatti, próximo ao centro da cidade (o percurso de ônibus durava aproximadamente uma hora).

A qualidade da mobilidade entre o bairro e o restante da cidade é representativa da condição de vulnerabilidade que marcou os DICs. A questão da mobilidade do indivíduo urbano não está apenas relacionada ao ir e vir ao centro da cidade, mas está associada também às características do espaço onde o citadino está fixado (permanência).

Enquanto local da morada (e/ou área em que se permanece), a vida urbana se centra, de vários modos, no bairro. Ir e vir dentro do bairro são movimentos ligados ao suprimento de necessidades e desejos mais prementes na manutenção diária da vida. Certa mobilidade satisfatória dentro do bairro, ligada ao seu conteúdo socioespacial enquanto provedor dessas necessidades ou desejos, qualifica a permanência no bairro.

Com o urbano não consolidado (ainda na década de 1990, pequenas manadas de bois atravessavam algumas ruas, lembra um morador) e o comércio sendo representado somente pelas pequenas iniciativas de um ou outro morador, as compras de mantimentos para a semana ou do pão francês para o café da manhã, por exemplo, significavam deslocamentos consideráveis através dos DICs.

Um morador, que se mudou para os DICs na década de 1990, conta que restringia o hábito de comer pão francês no café da manhã aos finais de semana, pois, nos dias úteis, não tinha tempo de se deslocar do DIC V, junto à Av. Suaçuna, até o interior do DIC III para comprar pão na pequena padaria que havia ali. Esse mesmo morador também conta sobre a necessidade de se deslocar a pé até a Av. Itamaraty para comprar produtos corriqueiros no único mercado que havia nas imediações.

As compras do mês também podiam significar gastos relativamente mais altos. Uma moradora do DIC IV, desde meados da década de 1980, conta que tinha de ir fazer compras em mercados distantes dos DICs e, por não possuir veículo próprio, tinha de pagar táxi para levar as compras até sua casa.

Notável, ainda, é o caso do Posto de Saúde do DIC III que, até o final da década de 1990, era o único referencial mais próximo de serviço de saúde público para os moradores dos DICs II, III, IV, V. Em meados de 1990, o contingente populacional a ser atendido pelo posto de saúde aumentou com o estabelecimento do DIC 5 de Março e de outros bairros (originados a partir de invasões de terras públicas) nos limites dos DICs. 
Para muitos, era necessário vencer grandes distâncias a pé para consultas médicas ou pequenas emergências - além de problemas gerados pela dificuldade do posto em atender satisfatoriamente à demanda crescente.

Observando o quadro de reveses na vivência dos primeiros anos neste conjunto habitacional, insistimos em perguntar aos moradores mais antigos: por que permanecer nesse bairro marcado pelas lidas constantes contra as adversidades? As respostas, substancialmente parecidas, nos direcionam para o significado dos DICs na vida de seus moradores: ficaram porque foi nesse bairro que conseguiram suas casas próprias.

$\mathrm{O}$ espaço em que se permanece pode se tornar, ao longo do tempo, um espaço apropriado. Os DICs enquanto bairro são uma área da cidade na qual indivíduos convivem intimamente com o espaço, pelo qual se movem em função da realização das atividades mais rotineiras. E a ideia de apropriação do espaço nos direciona para a compreensão do papel do bairro na vida urbana: é na apropriação que pode repousar a ideia de território.

\section{Permanência e identidade territorial nos DICs}

Há diferentes perspectivas para a compreensão e utilização do território enquanto categoria analítica. Rogério Haesbaert, quando discute território e des-territorialização, aponta três perspectivas gerais para o entendimento do território: a perspectiva jurídico-política, a cultural e a econômica (HAESBAERT, 2004). O que une essas perspectivas e, consequentemente, orienta a ideia de território é a apropriação de uma parcela do espaço, com certo exercício de poder sobre ela (SACK, 1986).

As narrativas revelam processos de territorialização na experiência urbana dos DICs, ao denotarem as relações que os indivíduos estabeleceram com o espaço na formação de uma comunidade esteada nele e na consequente formação de uma identidade. Esses laços comunitários são, sobretudo, enfatizados pelos moradores mais antigos, que compartilharam os tempos com mais riscos e permaneceram.

A fala dos moradores revela que o território se desenvolve no envolvimento necessário com o espaço. Esse envolvimento é necessário pois é o espaço do entorno da casa, espaço do qual o indivíduo depende para realizar a manutenção diária da vida. É na dependência da configuração desse espaço que está esteado o processo de apreensão e o 
desejo de conformação deste espaço, que desemboca no desenvolvimento de uma territorialidade própria do urbano.

Utilizamos o binômio território-vivido para denotar que os processos que conformam essa territorialidade (relacionados ao poder explícito ou implícito sobre determinada porção de espaço, a delimitação desta porção e as implicações de a ela pertencer) se realizam na escala do indivíduo, da experiência vivida. Além disso, pensamos um território cuja base é o lugar (relação estreita entre espaço e indivíduo), um espaço utilizado e pensado cotidianamente (HOLZER, 1997; BONNEMAISON, 2002).

São extensos os territórios vividos dos primeiros moradores dos DICs, pois a mobilidade interna, caracterizada pelas consideráveis distâncias dos serviços e/ou equipamentos sociais (como posto de saúde ou escola) faz com que o movimento de territorialização se estenda por grandes áreas. A divisão entre os diversos DICs não ganha muita força na vivência destes, pois, com esta mobilidade estendida, o território e o lugar não se conformam por essas divisões. A confluência aos poucos estabelecimentos necessários ao cotidiano serviu como promotor de laços entre indivíduos que residem consideravelmente distantes uns dos outros, mas submetidos às mesmas condições de vida engendradas pela configuração territorial dos DICs. Ainda hoje, nos bairros é comum avistar grupos de crianças ou adolescentes se encontrando, caminhando ou brincando pelas ruas, tendo em comum, muitas vezes, não a proximidade de suas casas, mas o coleguismo originado nas escolas, que reúnem pessoas de variados pontos dos DICs. ${ }^{4}$ Entre os moradores, dizer que mora no DIC III ou no DIC V, por exemplo, serve para conotar muito mais localização e época em que o morador chegou aos DICs do que diferenças consideráveis nas características da experiência baseadas no espaço. ${ }^{5}$ No

\footnotetext{
${ }^{4}$ Isso é especialmente relevante ao observarmos que as escolas não têm o atendimento direcionado à proximidade dos alunos em relação a ela, mas à sua idade. Por exemplo, adolescentes dos DICs II, III, IV, V, 5 de Março e das invasões, que cursem do $3^{\circ}$ ciclo do ensino fundamental em diante, estudam na escola pública do DIC III.

5 Escapa a esta indiferenciação entre os DICs o DIC 5 de Março. Sendo o último dos DICs entregues, é geralmente denominado entre os moradores dos DICs como "Invasão"; a demora na conclusão e entrega das casas propulsionou a invasão destas, tanto por indivíduos que já vinham pagando o financiamento quanto por indivíduos que não estavam inscritos no programa de habitação. A invasão, em fins da década de 1990 (em um 5 de Março), foi então legalizada no início da década de 2000. Por ocasião dos trabalhos de campo, foram observadas as obras para o primeiro asfaltamento dentro do DIC 5 de Março.
} 
entanto, é importante atentar também que as divisões ainda contam para fins administrativos, como no caso das associações de bairro.

David Seamon, estudando fenomenologicamente os movimentos diários dos indivíduos em consonância com determinados espaços, atenta para a existência de rotinas espaço-temporais, chamando-as de balé do lugar (place-ballet) (SEAMON, 1980). Os movimentos diários dos moradores conformam uma rotina espaço-temporal. A coincidência de rotinas espaço-temporais de diferentes indivíduos tem como consequência o encontro não só de vizinhos, mas de qualquer morador do bairro. São esses encontros - ao estabelecerem relações primárias — que promovem a confluência do território-vivido dos indivíduos, possibilitando o desenvolvimento de um território vivido coletivo (DE PAULA, 2007). O balé do lugar funda os territórios vividos.

O território vivido pelos moradores se estende para além dos espaços imediatos das casas, uma vez que a configuração espacial dos DICs (os elementos que promoviam a confluência dos moradores estando dispersos pelo bairro) fazia com que o balé do lugar se estendesse por quilômetros. As relações primárias entre os indivíduos se estenderam para além das estabelecidas com os vizinhos contíguos. $\mathrm{O}$ elo que expressa este território e as relações entre os moradores dos DICs é a identidade territorial.

A territorialização tem relação intrínseca com a formação da identidade territorial, a qual remete à associação tríplice entre: 1) como é determinado território; 2) quem vive nele; e 3) como é viver nele. A identidade territorial pode surgir como base para a formação de laços comunitários em um bairro (DE PAULA, MARANDOLA JR. e HOGAN, 2007). Ela institucionaliza, de certa forma, a singularidade dos indivíduos (em relação a outros indivíduos que moram em outras áreas da cidade), baseando-a na vivência conjunta do mesmo território (bairro). Mathias Le Bossé, ao discutir as perspectivas para o estudo da identidade pela Geografia, coloca a importância da territorialidade na interface entre lugar e identidade.

No sentido das modalidades práticas e simbólicas pelas quais um grupo define e controla seu território, a territorialidade revela a identidade do lugar; ela é, ao mesmo tempo, o

\footnotetext{
${ }^{6}$ A própria COHAB, atenta uma funcionária do Posto de Saúde do DIC III, dispõe uma construção para a sede de bairro. Havia, no início de cada DIC, uma réplica de casa ou apartamento para que os compradores das habitações pudessem observar a disposição e o tamanho de cômodos. Radicadas as habitações, essas réplicas foram então disponibilizadas como sede de associações de bairros.
} 
produto e a expressão de um ponto de vista interno e inclusivo. (LE BOSSÉ, 2004, p. 173).

Esse ponto de vista interno e inclusivo, quanto mais forte, melhor expressa o sentimento de uma "comunidade de vida e destino" (BAUMAN, 2005, p. 17), baseada, no caso da identidade territorial, na própria experiência de conviver no mesmo espaço, de historicidade e geograficidade específicos. Os processos de estabelecimento de lugar e de identidade territorial subsidiam, assim, laços comunitários.

Permanecer nos DICs implica o movimento de recursos para lidar com o quadro de adversidades que os caracterizava. É nesse ponto que surge a importância dos laços comunitários como recurso à vulnerabilidade difundida. $\mathrm{O}$ estabelecimento do sentimento de lugar e a identidade territorial concorrem, então, para consolidar esses laços. E, além disso, nas narrativas dos moradores dos DICs, fica implícito que o isolamento em relação à cidade, a mobilidade interna estendida por grandes distâncias, a confluência aos mesmos pontos e o enfrentamento das mesmas adversidades são cruciais nestes processos.

As redes de solidariedade e certa consciência de identidade territorial (consciência de que aqueles que ali vivem estão submetidos aos mesmos reveses) auxiliam no enfrentamento de perigos. Não raro, por exemplo, indivíduos que possuíam carro transportavam outros em uma emergência médica. A importância da coesão da comunidade também se refletiu na ação da Associação de Bairro do DIC IV, por exemplo, para a organização dos moradores no pagamento e na cobrança pelo asfaltamento das ruas desse DIC entre os anos de 1994 e 1995.

O lazer, enquanto fator de confluência, também promove o estabelecimento do sentimento de lugar e a formação de laços comunitários. A moradora do DIC IV conta que o bar da Fátima, aonde vai desde idos da década de 1980 tomar cerveja, é o mesmo em que se sentava para, antes de pegar o ônibus, trocar os sapatos sujos de terra e barro das ruas do bairro por sapatos limpos, para andar pela cidade. O lazer também reflete o processo de adequação do território em que se vive, como no caso dos campos de futebol abertos nas várzeas. Times e campeonatos de futebol são organizados e, em alguns campos, os moradores construíram arquibancadas, bancos ou mesmo pequenas praças para assistir aos jogos.

Essas modalidades práticas e simbólicas de apropriação e controle do território perfazem a paisagem dos DICs, refletindo a apropriação e a constituição do território. Elas estão explicitadas na medida em que certo ponto de vista interno perpassa a identidade territorial e se aplica na 
apreensão e adequação deste espaço às necessidades ou desejos daqueles que nele vivem.

Ocorrem também outras formas de apropriação/adequação do espaço, como a idealização de pequenas praças pelos moradores, a plantação maciça de árvores em determinadas avenidas ou a recorrente tomada de terrenos de várzeas para a construção de pequenas hortas ou jardins. Foi perguntado (corriqueiramente) a um morador sobre quem era o dono de uma grande horta à beira de um córrego no limite sul do DIC IV. O senhor de idade respondeu, sorrindo, que o terreno era da prefeitura; mas a horta, quem mantinha, era um homem da rua de cima. E o morador ainda completou: "ele cuida direitinho pra nós".

A paisagem transformada foi construída em direção ao que os moradores esperam ou desejam para seu território, para qualificar sua permanência ali. Essa transformação da paisagem denota a apropriação e o exercício de poder sobre o espaço, assim como a existência de um discurso interno e coletivo sobre este espaço. Talvez a maior expressão dessa transformação (quiçá pela magnitude) seja a grande praça esportiva concebida e construída pelos próprios moradores no DIC III, que, durante campeonatos de futebol, recebe um grande contingente de pessoas.

Um morador contou com orgulho sobre a construção dessa praça de esportes. Antes, o local da praça era um terreno baldio, caracterizado por uma quebra abrupta de declividade, onde os moradores jogavam, descuidadamente, entulhos. Ele acha irônico que essa ação, ao longo dos anos, tenha proporcionado o aterro do terreno e a possibilidade de sua planificação e posterior construção do campo de futebol e estruturas associadas.

Augustin Berque, problematizando a questão da paisagem para a Geografia Cultural, expõe a importância da construção e reconstrução do espaço. Segundo ele, a paisagem "[...] existe, em primeiro lugar, na sua relação com um sujeito coletivo: a sociedade que a produziu, que a reproduz e a transforma em função de uma certa lógica." (BERQUE, 1998, p. 84 - grifo do autor). A lógica, nesse caso, está relacionada à própria adequação do espaço do bairro às necessidades e aos desejos daqueles que ali vivem.

A identidade territorial dos DICs expressa a particularidade desse espaço. A ideia de certa singularidade (do espaço e das pessoas que ali vivem) associada ao termo bairro está pautada, sobretudo, na construção de identidades territoriais, mas se relaciona também à identificação ligada à segurança, à familiaridade e ao pertencimento. É um processo de seleção e 
identificação daquele (e daquilo) que pertence e não pertence, como ocorreu várias vezes em campo, quando a reação dos moradores era diferente ao saber que a pesquisadora era uma antiga moradora do bairro: muito mais receptiva e com um orgulho territorial por esta estar ali para realizar uma pesquisa pela Unicamp.

No entanto, atentos à amplitude da experiência urbana (na subjetividade e na intersubjetividade podem estar congregadas diferentes visões sobre a mesma área da cidade), essa identidade territorial pode ter uma face externa e, neste caso, a identificação do bairro (os símbolos que o distinguem dentro da cidade) pode ser mediada por imagens e discursos pouco afeitos à vivência do lugar (COSTA, 1999). Por exemplo, a identidade territorial gerada mormente fora dos DICs o caracteriza como espaço sob a égide de todo o tipo de reveses urbanos. Porém, quando se discorre sobre a identidade territorial desenvolvida no interior do próprio território, abre-se a possibilidade de uma compreensão mais concreta do lugar. Essa compreensão fundada na (con)vivência pode manifestar não só uma imagem diferente desse espaço — em relação à imagem produzida fora do bairro - , mas, além disso, apresentar a maneira pela qual essa identidade territorial congrega e norteia a relação entre os indivíduos e o espaço em seus territórios vividos.

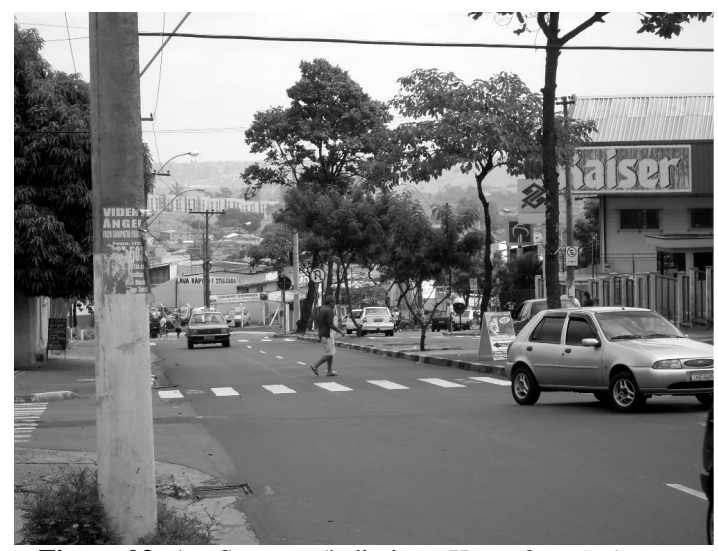

Figura 03: Av. Suaçuna (à direita o Hortoshopping)

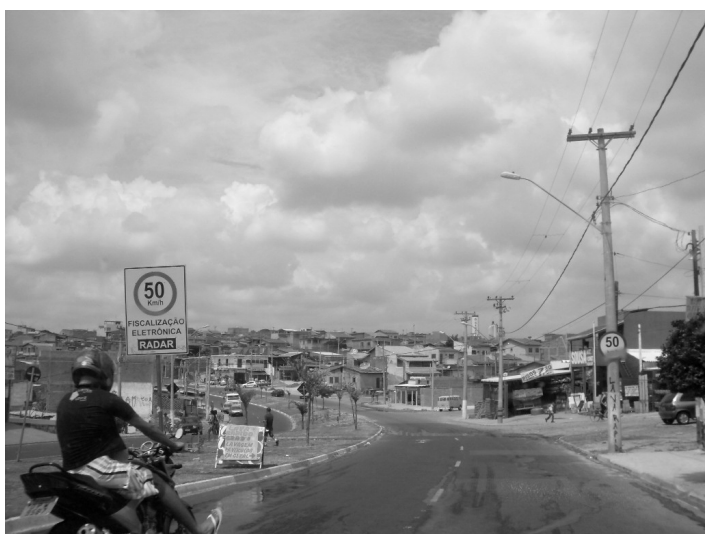

Figura 04: Av. Suaçuna (no DIC 5 de Março) 


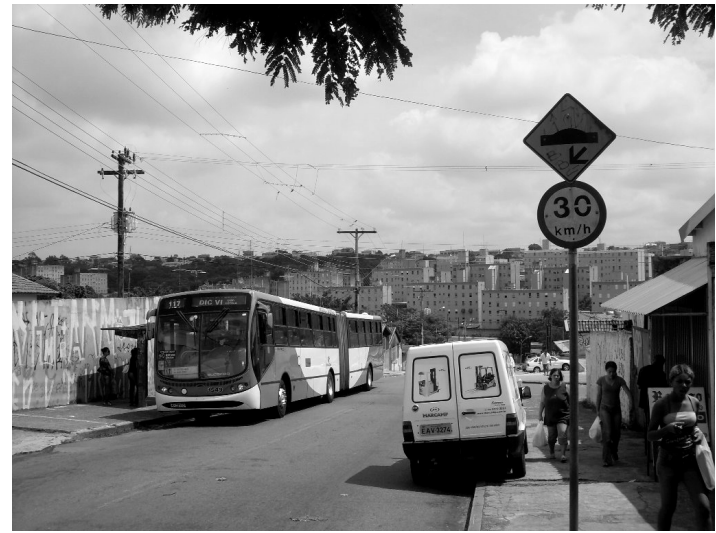

Figura 05: R. Jorge P. Mendonça (ao fundo o DIC I)

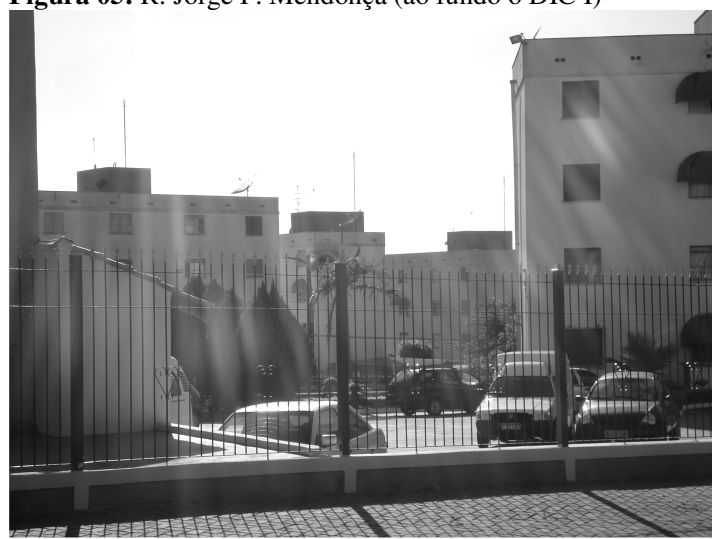

Figura 07: Padronização (DIC V)

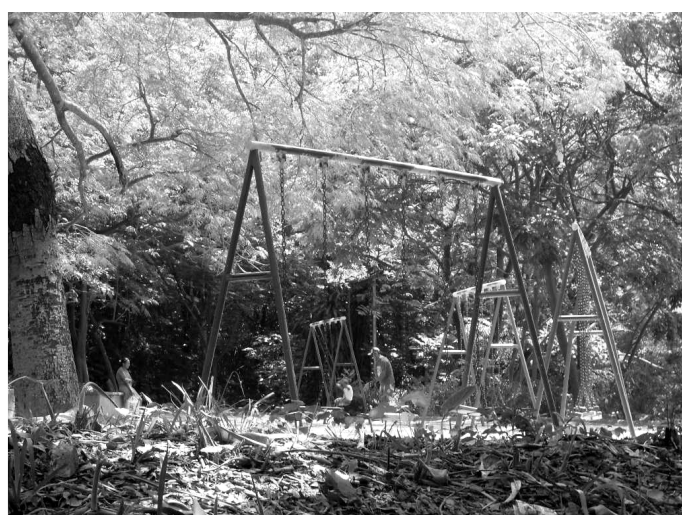

Figura 06: Bosque do DIC I

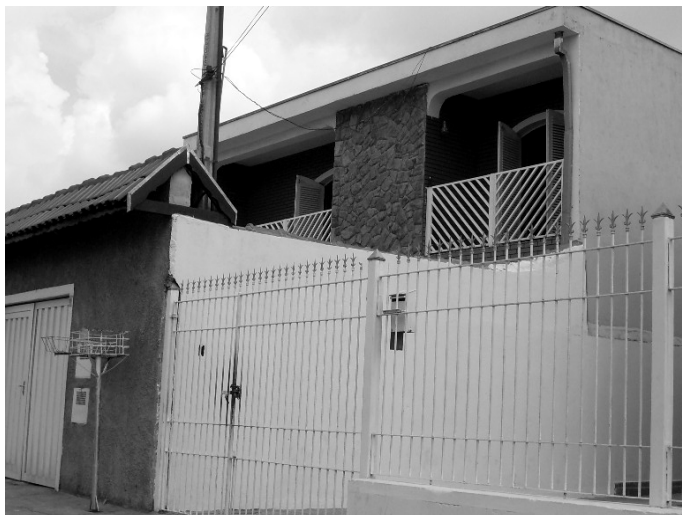

Figura 08: Perda de padronização das casas (DIC IV)

Figuras 03 a 08: Paisagens dos DICs, Campinas (SP). A consolidação urbana dos DICs vem ganhando novas dimensões. Atualmente, as últimas ruas de terra estão sendo asfaltadas, os serviços oferecidos na Av. Suaçuna vêm se sofisticando (novas agências bancárias, vendas de bens de consumo duráveis). A manutenção constante dos bosques, a construção de novos equipamentos urbanos reforçam, para os moradores, a melhoria da qualidade das condições de vida neste bairro e, no mesmo movimento, a diminuição dos riscos e perigos. (Fotos: F.C.P, 2006 e 2009). 


\section{Consolidação urbana: territórios vividos nos DICs}

"Quando mato vira bosque é porque melhorou, não é?", perguntou retoricamente, entre risos, a moradora do DIC IV. Na fala dos moradores, quando colocam ênfase entre o início do bairro e suas condições atuais, dizem que o bairro agora é o paraíso. A afirmação recorrente é: "Agora, aqui tem tudo".

Os DICs cresceram, as últimas residências já foram entregues, as ruas estão asfaltadas. O descompasso entre o projeto de uma zona residencial urbana onde o urbano era débil é descaracterizado na sua consolidação urbana. Persiste a imagem de bairro (para aqueles que não vivem os DICs) pontuado por variadas adversidades; no entanto, os moradores revelam (muitas vezes) o contrário.

Ir até a cidade já não pressupõe grandes sacrifícios. Novas linhas de ônibus, novos itinerários e a diminuição do intervalo de passagem entre um ônibus e outro melhoraram a situação do transporte local. E interessante atentar para a importância de uma linha de ônibus que sai do DIC I, atravessa os outros DICs (recolhendo passageiros) e faz um caminho mais rápido até a cidade, através da Rodovia Santos Dumont e ainda passa pelo centro de Campinas, parando em seus pontos mais significativos.

No entanto, ir à cidade já não é tão premente quanto antigamente. $\mathrm{O}$ comércio se fortaleceu ao longo de algumas avenidas, que se tornaram vias principais, ao congregarem, além do comércio, os itinerários dos ônibus e os acessos a serviços como postos de saúdes, escolas, creches. A permanência no bairro já não envolve tantas carências como antes. Por exemplo, um recorrente símbolo de melhoria foi a abertura de um supermercado entre os DICs IV e V em meados da década de 1990.

Outro símbolo de melhorias são os serviços oferecidos no que se convenciona chamar, em Campinas, centro da Região Ouro Verde. A associação do Terminal Ouro Verde, do Hortoshopping Ouro Verde, das agências bancárias e do Pronto Socorro Ouro Verde (na Av. Suaçuna esquina com a Av. Ruy Rodrigues) promove forte fluxo nessa área, notadamente nos finais de semana. Ainda cabe citar a abertura da filial de uma grande rede de hipermercados na Av. Ruy Rodrigues, relativamente próximo desse centro. $\mathrm{O}$ balé do lugar que se realiza em função dos movimentos dos indivíduos pelo bairro é orientado pela presença dos novos equipamentos urbanos. 
Entretanto, dentro dos DICs o território vivido não é apenas um, estendido sobre toda a área. $\mathrm{Na}$ fala dos moradores, encontramos a expressão de dois movimentos de territorialização, esteados em dois balés dos lugares distintos. Esses balés dos lugares se consolidaram a partir de duas centralidades dentro dos DICs: nos DICs I e VI, na rua Jorge P. Mendonça; e nos DICs II, III, IV, V e 5 de Março, na rua Carmen A. de Nicoletti e na Av. Suaçuna. No entanto, esses centros não fragmentam a identidade única dos DICs. Apesar da existência de dois territórios vividos dentro dos DICs, conta para a existência de uma identidade territorial única peso do centro da Região Ouro Verde: figurando como fator de união desses dois territórios vividos, na medida em que é ponto de confluência (área comum a que recorrem) dos moradores dos DICs; assim como a importância da toponímia DICs, que remete a certa coesão socioespacial e ao espaço originado a partir do programa de habitação popular. Ledrut (1971, p. 11), discorrendo sobre a importância de centros de recursos dentro dos bairros, auxilia a compreensão do papel das centralidades na conformação do bairro urbano:

\begin{abstract}
A necessidade suscitada pelo afastamento vivido vai levar à criação de vários serviços, acentuando assim a individualização do bairro, sob o aspecto da sua organização e forma. O bairro deve, na verdade, sua unidade aos seus recursos e aos comportamentos sociais a ele ligados. A cidade e suas partes vivem ao assegurar um certo número de serviços, cada vez em maior número, no mundo moderno. [...] A frequência aos estabelecimentos comerciais, às escolas, às salas de reunião e de espetáculos que se instalaram dentro de certo perímetro contribui para a formação de um bairro.
\end{abstract}

O bairro, por ser local de permanência e estar notadamente distante do centro da cidade, precisa ser um espaço dotado de certa autonomia no sentido de dar base ao devir cotidiano. Essa autonomia está ligada, principalmente, às características da mobilidade - não só em relação à qualidade das redes, mas em relação às causas do movimento e sua necessidade - e às possibilidades que a configuração espacial do bairro oferece para aqueles que ali permanecem.

Ao promover a confluência (a rotina espaço-temporal), as centralidades também denotam limites desses territórios. As duas territorialidades dos DICs são facilmente explicitadas pelos moradores. Quando foi perguntado a estes se conhecem toda a área dos DICs, atestaram que sim. No entanto, a mesma ressalva é recorrente: por exemplo, moradores dos DICs II, III, IV, V atestam não conhecer tão bem 
a área dos DICs I e VI. Eles não têm a necessidade cotidiana de ir até aquela área; a territorialidade vivida, o balé do lugar ao qual pertencem não se estende até a outra área dos DICs. Os limites entre esses dois territórios se dão - na compreensão dos moradores - pelo córrego em interface entre o DIC VI e os DICs II e III; como se testemunhasse que, a depender de qual lado do córrego o indivíduo mora, ele participará de tal ou qual balé do lugar.

O entendimento do papel do bairro na vivência da cidade ficou patente na fala do morador do DIC VI. Quando foi perguntado a ele a qual posto de saúde costumava recorrer, uma vez que parecia não haver nenhum nas imediações, ele respondeu que ia ao Posto de Saúde do DIC I. Perguntado, ainda, se este não era muito longe de sua casa, disse que não, não era, e acrescentou (gesticulando, apontando limites) que o bairro era aquele ali: da sua casa ao Posto de Saúde do DIC I, onde estava também o supermercado onde costuma fazer as compras mais corriqueiras, assim como o local onde se beneficia de outros serviços situados naquela rua (a Jorge P. Mendonça).

Dentro da experiência urbana pode ser compreendido que o bairro surge como território vivido. O local da residência é o ponto zero a partir do qual o indivíduo organiza seus movimentos na cidade (por que ir, para onde ir, as condições dessa mobilidade). É o espaço provedor das necessidades do dia a dia (contendo elementos espaciais que promovem a permanência, os serviços de que este espaço dispõe, o nível de satisfação que possa oferecer). De dentro deste papel do bairro advém, ao abordarmos os DICs, que, quando os caracteres de um espaço que se propõe urbano (como foi concebida a construção dos DICs) evoluem nos elementos que orientam este modo de vida - tanto pela ação direta do poder público como pela ação sobre este espaço pelos próprios moradores - , surge, entre os indivíduos, a percepção de uma menor vulnerabilidade.

\section{Da vulnerabilidade à constituição do território}

O processo de consolidação urbana dos DICs analisado em nossa pesquisa revela de forma interessante como a dimensão da vulnerabilidade é um processo e, ao mesmo tempo, uma dimensão intrínseca da nossa sociedade contemporânea. Alguns dos elementos vividos em termos de riscos e perigos são características espaciais de um bairro com falta de infraestrutura urbana, o que ao longo do tempo sofre a intervenção do poder público, do poder privado e dos próprios moradores. Esses três 
agentes dão origem a processos de territorialização que visam apropriar-se, material ou simbolicamente, do espaço do bairro. A identidade territorial é constituída na relação entre esses agentes, sendo a participação de cada elemento central para compreender a experiência urbana e a evolução da vulnerabilidade.

No caso dos DICs, a ação premeditada e frequente dos moradores em tomarem atitudes pró-ativas na consolidação do bairro, potencializando sua condição de permanência e mobilidade, é central na constituição da identidade territorial.

Essa identidade territorial é central na compreensão não apenas da diminuição da percepção dos perigos, mas sobretudo na consolidação e na acumulação de capital social e conhecimento ambiental capaz de permitir dar melhores respostas, no longo prazo, aos perigos. A constituição do bairro enquanto um território vivido estabelece a liga que aciona e potencializa redes sociais, recursos ambientais, estruturas urbanas e recursos econômicos em prol da comunidade. O tempo de experiência e o conhecimento cumulativo é materializado no espaço, tornando o território condição primeira para a proteção e a segurança.

Perseguindo o "viver no bairro", caminhamos em direção ao território enquanto valor. Partindo desse ponto, as considerações de Zilá Mesquita contribuem para esta busca, na medida em que se aproxima do território e do valor deste ao homem enquanto estado/movimento natural que caracteriza nossa existência:

O território é o que é próximo; é o mais próximo de nós. É o que nos liga ao mundo. Tem a ver com a proximidade tal como existe no espaço concreto, mas não se fixa a ordens de grandeza para estabelecer a sua dimensão ou seu perímetro. É o espaço que tem significação individual, e social. Por isso ele se estende até onde vai a territorialidade. Esta é aqui entendida como a projeção de nossa identidade sobre o território. (MESQUITA, 1995, p. 83).

Território implica proximidade, relação direta com o espaço. $\mathrm{O}$ bairro, ao ser local de permanência e ponto zero a partir do qual se estrutura nossa mobilidade, é espaço privilegiado de formação de territorialidade em nossa experiência urbana.

Na consolidação da territorialidade, por meio do balé do lugar, podese originar uma sociabilidade, que corresponde justamente à ideia de 
coesão socioespacial, que (tradicionalmente) está associada à ideia de bairro.

No que diz respeito aos DICs, é esta coesão (expressa pela identidade territorial, base dos laços comunitários) que permitiu a diminuição da vulnerabilidade não apenas na forma de ajuda mútua imediata, mas também na forma de ações para intervir no lugar (em detrimento de necessidades/desejos dos próprios moradores).

Mobilidade e permanência, enquanto atributos essenciais do urbano, constituem, portanto, os territórios vividos e a territorialidade do bairro, fornecendo a base existencial e social para que a vulnerabilidade seja entendida como elemento intrínseco da dimensão socioespacial urbana.

\section{“QUANDO MATO VIRA BOSQUE É PORQUE MELHOROU, NÃO É?” MOBILIDADES E PERMANÊNCIAS CONSTITUINDO TERRITÓRIOS URBANOS}

Resumo: Bairros populares, localizados na fronteira urbano-rural, são caracterizados por uma condição generalizada de vulnerabilidade no momento de sua constituição. A precariedade da infraestrutura urbana e a própria condição social dos moradores (não raro migrantes) promove uma diversidade de reveses. Neste artigo, discutirmos um destes bairros na cidade de Campinas (SP): os DICs (Distritos Industriais de Campinas). A partir de uma abordagem humanista-fenomenológica, procuramos compreender a experiência urbana dos próprios moradores no devir geográfico que marcou o bairro durante sua consolidação urbana. Entre o início precário e a consolidação do bairro, as narrativas dos moradores revelam uma tensão entre mobilidade e permanência, a qual se reflete na qualidade e em características destas enquanto estruturadoras da experiência urbana a partir do lugar (bairro). Dentro deste contexto, é o desenvolvimento de territorialidades e da identidade territorial que auxiliou o enfrentamento dos reveses que marcaram o início dos DICs, tornando sua compreensão fundamental para pensar a vulnerabilidade enquanto processo experienciado cotidianamente.

Palavras-chave: bairro, identidade territorial, território vivido, vulnerabilidade, DICs (Campinas-SP)

\section{"WHEN WILDERNESS BECOMES WOODS, IT MEANS IMPROVEMENT, DOESN'T IT?" MOBILITIES AND PERMANENCE FORMING URBAN TERRITORIALITIES}


Abstract: Popular neighborhoods, located in the urban-rural boundaries, are characterized by a condition of generalized vulnerability at the time of their formation. The precariousness of urban infrastructure and the social condition of people (often migrants) lead to several setbacks. In this paper, we discuss one of these neighborhoods in the city of Campinas (SP): the DICs (Industrial Districts of Campinas). From a humanisticphenomenological approach, we make an attempt to understand the urban experience of the residents in the geographical moment that marked the urban district during its consolidation. Between the precarious start and the consolidation of the neighborhood, the narratives of residents reveal a tension between mobility and permanence, which influences their quality and characteristics as responsible for structuring the urban experience from the place (neighborhood). Within this context, the development of territoriality and territorial identity has helped to face the setbacks that marked the beginning of the IDCs, and this comprehension is fundamental to think about the vulnerability as a process experienced every day.

Keywords: neighborhood, territorial identity, lived territory, vulnerability, DICs (Campinas-SP)

\section{BIBLIOGRAFIA}

BAUMAN, Z. (2005) Identidade. (trad. Carlos A. Medeiros). Jorge Zahar. Rio de Janeiro

BECKER, H. S. (1997) Métodos de pesquisa em Ciências sociais. (trad. Marco Estevão e Renato Aguiar) 3ed. Hucitec. São Paulo.

BERQUE, A. (1998) Paisagem-marca, paisagem-matriz: elememtos da problemática para uma Geografia Cultural. In: CORRÊA, R. L. e ROSENDAHL, Z. (orgs.) Paisagem, tempo e cultura. EdUERJ. Rio de Janeiro.

BILAC, E. D. (2006) Gênero, vulnerabilidade das famílias e capital social: algumas reflexões. In: CUNHA, José M. P. da. (org.) Novas metrópoles paulistas: população, vulnerabilidade e segregação. NEPO/UNICAMP. Campinas.

BONNEMAISON, J. (2002) Viagem em torno do território. In: CORREA, R. L. e ROSENDAHL, Z. (orgs.) Geografia cultural: um século (3). EdUERJ. Rio de Janeiro.

CASTELlS, M. (1983) A questão urbana. (trad. Arlene Caetano) Paz e Terra. Rio de Janeiro. 
COSTA, A. F. (1999) Sociedade de bairro: dinâmicas sociais da identidade cultural. Oeiras: Celta.

DE PAULA, F. C. (2007) Geografia de bairro: experiência urbana e territórios vividos no bairro Bosque.. (Monografia) Campinas: Instituto de Geociências/Universidade Estadual de Campinas. Campinas.

DE PAULA, F. C.; MARANDOLA JR., E. e HOGAN, D. J. (2007) O bairro, lugar na metrópole: riscos e vulnerabilidades no São Bernardo, Campinas. Caderno de Geografia, v. 17, n. 28, p. 31-58. Belo Horizonte. GEORGE, P. (1983) Geografia Urbana. DIFEL. São Paulo.

HAESBAERT, R. (2004) O mito da desterritorialização: do fim dos territórios à multiterritorialidade. Bertrand Brasil. Rio de Janeiro.

HAY, I. (2005) (ed.) Qualitative research methods in Human Geography. 2ed. Oxford University Press. Melbourne.

HOGAN, D. J. e MARANDOLA JR., E. (2006) Para uma conceituação interdisciplinar de vulnerabilidade. In: CUNHA, J. M. (org.) Novas metrópoles paulistas: população, vulnerabilidade e segregação. NEPO/Unicamp, Campinas.

HOLZER, W. (1997) Uma discussão fenomenológica sobre os conceitos de paisagem e lugar, território e meio ambiente. Território, ano II, $\mathrm{n}^{\circ} 3$, p. 77-85. Rio de Janeiro.

(1998) Paisagem e lugar: um estudo fenomenológico sobre o Brasil do século XVI. 233p. Tese (Doutorado em Geografia Humana) Faculdade de Filosofia, Letras e Ciências Humanas, Universidade de São Paulo, São Paulo.

KOWARICK, L. (2002) Viver em risco: sobre a vulnerabilidade no Brasil urbano. Novos Estudos CEBRAP, n. 63, p. 09-30.

LE BOSSÉ, M. (2004) As questões de identidade em Geografia Cultural algumas concepções contemporâneas. In: CORRÊA, R. L. e ROSENDAHL, Z. (orgs.) Paisagens, textos e identidade. EdUERJ. Rio de Janeiro.

LEDRUT, R. (1971) Sociologia urbana. (trad.Maria H. S. Reis) Forense. Rio de Janiero.

LEMENHE, J. A. (1997) Paisagem urbana e utopias. In: SILVA, José Borzacchiello; COSTA, M. C.. e DANTAS, E. W. (orgs.) A cidade e o urbano: temas para debates. EUFC. Fortaleza.

MARANDOLA JR., E. (2005) Arqueologia fenomenológica: em busca da experiência. Terra Livre, AGB, ano 21, v.2, n.25, p.67-79.

(2008a) Habitar em Risco: mobilidade e vulnerabilidade na 
experiência metropolitana. 2008. 278f. Tese (Doutorado em Geografia) Instituto de Geociências, Universidade Estadual de Campinas. Campinas.

. (2008b) Mapeando "londrinas": imaginário e experiência urbana. Geografia, v. 33, n. 1, p. 103-126. Rio Claro.

MARICATO, E. (2001) Brasil cidades: alternativas para a crise urbana. Vozes. Petrópolis

MESQUITA, Z. (1995) Do território à consciência territorial. In: MESQUITA, Z. e BRANDÃO, C. R. (orgs). Territórios do cotidiano: uma introdução a novos olhares e experiências. UFGRS. Porto Alegre.

MUNFORD, L. (1982) A cidade na história: suas origens, transformações e perspectivas.Martins Fontes/Ed. UNB. São Paulo.

PICKLES, J. (1988) From fact-world to life-world: the phenomenological method and social science research. In: EYLES, J. e SMITH, D. (orgs.). Qualitatives methods in human Geography. Polity Press. Oxford.

SACK, R. D. (1986) Human territoriality: its theory and history. cambridge University Press. New York

SEAMON, D. (1980) Body-subject, time-space routines, and place-ballets. In: BUTTIMER, A. e SEAMON, D. (orgs.). The Human Experience of Space and Place. St. Martin's Press. New York.

SERRA, G. (1987) O espaço natural e a forma urbana. Nobel. São Paulo. 